\title{
O PRINCÍPIO DA PROPOCIONALIDADE E AS SANÇÕES PENAIS NOS CONTRATOS ADMINISTRATIVOS
}

\author{
FERNANDA KellnER DE Oliveira PALERMo
}

1. Introdução - 2. Contratos administrativos - 2.1. Considerações gerais - 2.2. Sanções nos contratos administrativos - 3. Relação do direito administrativo com outro ramos do direito - 3.1. Relação do direito administrativo com o direito constitucional - 3.2. Relação do direito administrativo com o direito penal - 4. Princípio da proporcionalidade - 4.1. Origem do princípio - 4.2. O princípio da proporcionalidade na teoria do direito - $4.3 \mathrm{~A}$ intervenção estatal sob a égide do princípio da proporcionalidade - 4.4 Requisitos de empregabilidade do princípio da proporcionalidade - 4.5 Correlações principiológicas - 5. Limites à atividade discricionária nos contratos administrativos - 6. Conclusões - 7. Referências bibliográficas

\section{Introdução}

Partindo-se da primícia de que um dos papéis que restam à Constituição na atualidade é o de que ela não esteja posta como um olhar sobre os problemas sociais, mas um olhar para estes problemas, com a finalidade de apontar e mostrar os caminhos para o futuro, é de suma importância a perquirição acerca de realidades contrastantes que solapam o ordenamento jurídico pátrio a cada dia.

Neste ínterim, surge o tema relativo ao princípio da proporcionalidade, resultante da influência positiva do direito alemão, onde foi primeiramente estudado. Este princípio, ao ser inferido num modelo de Estado social e democrático de direito, possui o condão de aprimoramento do sistema de garantias a ele imanente, na busca incessante do interesse social corroborado no interesse público.

O princípio da proporcionalidade, já obteve o reconhecimento básico de categoria fundante do direito, apesar de ainda não ser um princípio expresso contitucionalmente no direito pátrio.

* Advogada.

R. Dir. Adm.,

Rio de Janeiro, 227: 321-337,

jan./mar. 2002 
O que se espera, através da contribuição que doravante se venha a ter, é que este princípio. elevado à categoria de valor supremo da Constituição, passe a estar explicitado nela. possuindo dessarte, força vinculante para sua plena observância.

Especificamente, ao se retratar tema de direito administrativo relativo ao contrato, busca-se discorrer a respeito de questões que versam sobre as sanções nele contidas, através da análise de variáveis como, num primeiro plano, a aproximação do direito administrativo com outros ramos jurídicos, para somente após, de modo pormenorizado, tratar-se questões sobre o princípio da proporcionalidade, correlacionando-o com a afirmação de que seria razoável que a Administração Pública regulasse $o$ ato, e consequientemente $o$ contrato administrativo, de acordo com a necessidade social e todas as implicações que esta afirmação enseja.

O objetivo do presente trabalho configura-se na percepção de que a idéia de proporcionalidade está intrinsecamente ligada à idéia de necessidade, fazendo com que a intervenção do Estado na sociedade somente se legitime quando há a salvaguarda das garantias, o que torna esta necessidade indispensável ou inadiável, acerca da profundidade do fato concreto.

\section{Contratos administrativos}

\subsection{Considerações Gerais}

A iniciação da Administração Pública na faculdade de contratar, necessitou diferentes modos de conformação, para que se atentasse à vinculação entre entes públicos e privados. $O$ reconhecimento desta capacidade não implica necessariamente que esta se efetive em termos idênticos aos particulares.

Devido a esta necessidade de adaptação, surgiu a idéia de uma espécie de contrato diferente, daqueles praticados na área do direito privado. A esta nova espécie, conceituada como o acordo de vontades pelo qual é constituída, modificada ou extinta uma relação jurídico-administrativa, deu-se o nome de contrato administrativo.

De acordo com as lições do eminente professor português João Caupers ${ }^{1}$, dos diversos critérios propostos para distinguir os contratos administrativos dos contratos privados, os mais utilizados foram:

a) O critério da sujeição, assente na idéia de inferioridade do contraente privado;

b) $\mathrm{O}$ critério do objeto, com base no qual se considera contrato administrativo aquele que constitui, modifica ou extingue uma relação jurídica de direito administrativo;

c) O critério estatutário, que entronca na concepção do direito administrativo como o direito da Administração Pública.

Trata-se de um fenômeno pelo qual relações e situações que envolvem interesses dos cidadãos privados, que segundo os esquemas clássicos da ação administrativa

1 CAUPERS, J. Introdução ao direito administrativo. Lisboa: Ancora, 2000. p. 219. 
(baseada tradicionalmente na contraposição entre autoridade e liberdade) eram disciplinados através de procedimentos unilaterais da administração e, atualmente também por via administrativa, tendem cada vez mais a ser regulamentados por via convencional e, portanto, na base de um acordo entre ente privado e ente público. E o instrumento deste novo modelo de ação administrativa, organizado sobre o consenso e não já sobre a imposição é, fundamentalmente, o contrato, embora adaptado às peculiaridades das situações e das funções inéditas com as quais é chamado a confrontar-se.

O contrato administrativo no Direito Positivo brasileiro encontra-se disciplinado no artigo 22, XXVII, da Constituição Federal, o qual dispõe, in verbis: "compete à União expedir normas gerais sobre contratação, em todas as modalidades, para a Administração Pública, direta e indireta, incluídas as fundações instituídas e mantidas pelo Poder Público, nas diversas esferas de governo, e empresas sob seu controle". Estados e municípios legislarão para si, respeitadas estas normas gerais.

Ditas normas gerais, assim como a legislação específica da União, estão consubstanciadas na Lei 8.666/93, com as alterações introduzidas pela Lei 8.883/94. Nesta legislação está previsto o conjunto de prerrogativas em prol da Administração, que são exercitadas nos limites e termos da lei, a saber:

a) de modificá-lo, unilateralmente, para melhor adequação às finalidades de interesse público, mas com variações de quantitativos e preços cifrados ao disposto na lei;

b) extingui-lo, unilateralmente, nos casos especificados em lei;

c) fiscalizar-lhe a execução,

d) aplicar sanções motivadas pela inexecução total ou parcial do ajuste.

Por ocasião do presente trabalho, analisar-se-á mais detidamente a aplicabilidade das sanções aludidas acima.

\subsection{Sançôes nos contratos administrativos}

A lei 8.666/93 prevê sanções pela prática de comportamentos configuráveis como infrações administrativas (art. 86 a 88), assim como prevê também, sanções penais tanto para o agente público como para o contrato que incorram em certos comportamentos lesivos ao interesse público por ocasião dos contratos administrativos (arts. 89, parágrafo único, 90, 91, 92 e parágrafo único, 96 e 99).

Assim, o contrato que injustificadamente atrasar-se na execução de contrato assujeita-se a ser multado pela Administração, na forma e termos previstos no instrumento convocatório ou no contrato (art. 86).

Além disso, conforme o art. 87, a inexecução total ou parcial do contrato o expõe, garantida sempre a prévia defesa, a sofrer as sanções administrativas de advertência; multa, nos termos do instrumento convocatório; suspensão temporária de participar de licitação e impedimento de contratar com a Administração por dois anos e declaração de inidoneidade para contratar ou licitar enquanto perdurarem os motivos que a determinaram ou até sua reabilitação, que será concedida sempre que ressarcir a Administração pelos prejuízos que lhe haja causado e tenham transcorrido dois anos da aplicação da sanção. 
Tanto a suspensão do direito de contratar quanto a declaração de inidoneidade, só podem ser aplicadas no caso dos atos tipificados na lei como crimes, pois não se admitiria seu cabimento em outras hipóteses sem que existia prévia descrição legal de outros casos de seu cabimento.

Certos comportamentos, que vão contra o interesse público, praticados em relação a contratos administrativos são qualificados como crime. Na lei estão tipificados hipóteses de contrato efetuado sem licitação, foram das hipóteses legais permissivas; travamento de contrato como resultado de fraude, ajuste ou procedimento gravoso à competitividade que teria de presidi-lo; prorrogação contratual fora das hipóteses admissíveis; fraude, em prejuízo da Fazenda, como fruto de licitação ou contrato, consistente em elevação arbitrária de preços ou venda, como verdadeira ou perfeita, de mercadoria falsificada ou deteriorada; entrega de uma mercadoria por outra; alteração da substância, quantidade ou qualidade de mercadoria devida ou, de qualquer modo, tornar injustamente mais oneroso o contrato.

As penas estabelecidas são a de detenção, que varia de três meses a seis anos conforme a figura delituosa, e multa nunca inferior a $2 \%$ nem superior a $5 \%$ do valor do contrato. A lei prevê que qualquer pessoa poderá provocar o Ministério Público para propositura da competente ação penal (art. 101), admitindo-se, se este não a intentar no prazo legal, ação penal privada subsidiária (art. 103). O procedimento da ação penal é extremamente célere e está regulado nos arts. 104 e seguintes.

Odete Medaur $^{2}$ preleciona que "embora não esteja explícito, parece claro que somente poderão ser aplicadas as sanções previstas na lei e de modo proporcional à gravidade do fato". (grifo nosso).

O direito administrativo, ao regular institutos como o contrato administrativo, cominando-lhe aspecto sancionador, relaciona-se com outros ramos do direito. Doravante faz-se necessária a análise destas relações.

\section{Relação do direito administrativo com outros ramos do direito}

\subsection{Relação do direito administrativo com o direito constitucional}

Ao se relacionar com outros ramos do direito, o direito administrativo está circunscrito a perceber e definir o sistema ao qual faz parte, assim como com aquele sistema maior, do qual também faz parte.

Este sistema maior encontra-se indicado através de princípios, que certamente servem de alicerces para embasar todo um conjunto de normas que representam as leis constitucionais de um dado ordenamento jurídico.

Reconhecidamente, o direito administrativo e o direito constitucional se interpenetram, considerando suas últimas relações com o objeto Estado.

2 MEDAUAR, O. Direito administrativo moderno. 4.ed. rev. atual. e ampl. São Paulo: Revista dos Tribunais, 2000. p. 256. 
É através da explicitação dos princípios constitucionais do direito administrativo que se objetiva a evidente inserção conceitual.

Dentre os principais princípios apontados pelos doutrinadores, destacam-se os seguintes:

a) Princípio da supremacia do interesse público sobre o interesse privado (fundamenta-se na própria idéia de Estado);

b) Princípio da legalidade (arts. $5^{\circ}$, II. 37, caput, e 84, IV da C.F.);

c) Princípio da finalidade (mesmos fundamentos do princípio da legalidade);

d) Princípio da razoabilidade (mesmos dispositivos que os da legalidade e finalidade);

e) Princípio da proporcionalidade (por estar intrinsecamente ligado ao princípio da razoabilidade, radica-se também nos mesmos dispositivos);

f) Princípio da motivação (arts. $1^{\circ}$, II e parágrafo único, e $5^{\circ}$, XXXIV, da C.F.);

g) Princípio da impessoalidade (arts. 37, caput, e $5^{\circ}$, caput, da C.F.);

h) Princípio da publicidade (arts. 37, caput, e $5^{\circ}$, XXXIII e XXXIV, “b”, da C.F. C.F.);

i) Princípios do devido processo legal e da ampla defesa (art. $5^{\circ}$, LIV e LV, da

j) Princípio da moralidade administrativa (arts. 37, caput e parágrafo $4^{\circ}, 85, \mathrm{~V}$, e $5^{\circ}$, LXXIII, da C.F.);

k) Princípio do controle judicial dos atos administrativos (art. $5^{\circ}, \mathrm{XXXV}$ da C.F.);

1) Princípio da responsabilidade do Estado por atos administrativos (art. 37, parágrafo $6^{\circ}$, da C.F.);

m) Princípio da eficiência (art. 37, caput, da C.F.); e

n) Princípio da segurança jurídica.

\subsection{Relação do direito administrativo com o direito penal}

A atividade sancionadora da Administração Pública manifesta-se pela necessidade de impor aos administrados punições para assegurar o eficaz funcionamento dos serviços que estão a seu cargo.

Tal se verifica ora com relação a terceiros, quando se está ante o poder de polícia, ou com sujeitos que se encontram vinculados à entidade administrativa por vínculos hierárquicos (servidores) ou negociais (contratos administrativos).

Ao se deparar com as sanções penais e administrativas nos contratos administrativos, a Administração visa punir, a partir do instante que delas se ocupa, comportamentos que infringem deveres de obediência ou de colaboração dos indivíduos para com a atividade dos entes públicos na busca do interesse geral.

Em relação da Administração Pública com seu aspecto sancionador, também se reflete através de lindes principiológicas advindas dos princípios de direito penal, que podem ser agrupados do seguinte modo:

a) legalidade: somente à lei compete a definição das infrações administrativas e respectivas penas; 
b) tipicidade: a Administração, ao manejar sua competência punitiva, deve ajustar-se com precisão à descrição típica da norma que prevê a infração. A tipicidade enuncia uma das consequiências da adoção da reserva legal: a taxatividade. Segue-se daí não ser permitida a utilização, pelo administrador, da analogia, a fim de aplicar penas ao cidadão. ${ }^{3}$

c) culpabilidade: para fins de responsabilidade administrativa, este princípio impõe a ocorrência de dolo ou culpa por parte do agente da infração;

d) proporcionalidade: como o Poder Judiciário tem considerado este princípio angular na imposição de sanções penais administrativas, a ele será dedicado o próximo capítulo;

e) retroatividade da norma mais favorável: a lei penal não retroagirá, salvo se para beneficiar o réu;

f) non bis in idem: é inaceitável a dupla punição pelo mesmo fato;

g) non reformatio in pejus: a parte vencida não poderá, em decorrência do exercício de sua legítima pretensão em recorrer, ver a sua situação agravada quando para esse fim, nada postulou a Administração processante.

\section{Princípio da proporcionalidade}

\subsection{Origem do princípio}

\section{Como bem preleciona CANOTILHO ${ }^{4}$ :}

O princípio da proporcionalidade dizia primitivamente respeito ao problema da limitação do poder executivo, sendo considerado com medida para as restrições administrativas da liberdade individual. $\mathrm{Na}$ legislação portuguesa, é com este sentido que a teoria do estado o considera, já no século XVIII, como máxima suprapositiva, e que ele foi introduzido, no século XIX, no direito administrativo como princípio geral de direito de polícia. Posteriormente, o princípio da proporcionalidade em sentido amplo, também conhecido por princípio da proibição de excesso, foi erigido à dignidade de princípio constitucional.

É de se destacar o fato de que o princípio da proporcionalidade não encontra guarida expressa na Constituição Federal brasileira, apesar de que esta circunstância não impede seu reconhecimento, pois assim dispõe o parágrafo $2^{\circ}$ do artigo $5^{\circ}$ : “Os

3 Esta questão específica vem suscitando controvérsias, pois existem doutrinadores que atestam a invalidade de certas cláusulas abertas que pretendem qualificar como sancionável infração normativa de qualquer espécie. Ao tratar de respectivo tema, NOBRE JÚNIOR aduz que "a exemplo do direito penal, é de bom alvitre a aplicação do princípio da insignificância (ao qual far-se-á alusão adiante). Assim, $o$ aplicador da norma punitiva haverá de relevar as situações de não ocorrência de lesão a bens jurídicos da coletividade, escoimando de pena o infrator". NOBRE JÚNIOR, E. P. Sanções administrativas e princípios de direito penal. Revista de Direito Administrativo. Rio de Janeiro: Renovar, v.219, jan. - mar., 2000. p. 138.

4 CANOTILHO, J.J. Direito constitucional e teoria da constituição. 2.ed. Coimbra: Almedina, 1998. pp.259-260. 
direitos e garantias expressos nesta Constituição não excluem outros decorrentes do regime e dos princípios por ela adotados." (...)

\subsection{O princípio da proporcionalidade na teoria do direito}

Ao se considerar o princípio jurídico como o mandamento nuclear do sistema, por definir a lógica e a reacionalidade da normatividade, depreende-se que seu mecanismo de aplicação é muito mais complexo do que o esquema binário característico das regras.

Isto ocorre porque os princípios jurídicos não prevêem situações determinadas ou efeitos específicos que delas decorreriam. Os princípios, portanto, não estabelecem que, ocorrendo tal fato, será aplicada determinada sanção ou concedido certo benefício. Possuem um papel estruturante da ordem jurídica e da organização estatal como um todo, ao estabelecerem os pensamentos diretores do ordenamento das instituições, inclusive do próprio Estado, de uma disciplina legal ou de um instituto jurídico.

A distinção entre princípios e regras torna-se relevante, como assevera Humberto Bergmann ÁVILA ${ }^{5}$, pois:

A definição de princípios como normas imediatamente finalísticas e mediatamente de conduta explica sua importância relativamente a outras normas que compõem o ordenamento jurídico. Possuindo menor grau de determinação do comando e maior generalidade relativamente aos destinatários, os princípios correlacionam-se com um maior número de normas (princípios e regras), na medida em que essas se deixam conduzir ao conteúdo normativo dos princípios. Isso explica a hierarquia sintática e semântica que se estabelece entre princípios e demais normas do ordenamento e, conseqüentemente, a importância dos princípios na interpretação e aplicação do Direito.

Existem ocasiões em que há conflito entre princípios, ou entre eles e regras. $\mathrm{O}$ princípio da proporcionalidade é de grande valia nestas ocasiōes, pois pode ser usado como critério para solucionar da forma mais conveniente tal conflito, ao balancear a medida em que se aceita prioritariamente um e desatende o mínimo possível o outro princípio.

É imprescindível que se mencione a importância da difusão do princípio da proporcionalidade pelo ordenamento jurídico, nas considerações de Willis Santiago GUERRA FILHO ${ }^{6}$ :

O estabelecimento do princípio da proporcionalidade ao nível constitucional, com a função de intermediar o relacionamento entre as duas matérias mais importantes a serem disciplinadas em uma constituição, como são aquelas referentes aos direitos e garantias fundamentais dos indivíduos e à organização institucional dos

5 ÁVILA, H. B. A distinção entre princípios e regras e a redefinição do dever de proporcionalidade. Revista de Direito Administrativo. Rio de Janeiro: Renovar, v. 215, jan. - mar., 1999. p.168.

6 GUERRA FILHO, W. S. Processo constitucional e direitos fundamentais. São Paulo: Editora Celso Bastos, 1999. p.74. 
poderes estatais, já implica em aceitar a aplicação generalizada do princípio nos vários ramos do Direito.

Esta mesma concepção vem de encontro ao pensamento de Karl LARENZ ${ }^{7}$, que por sua vez, considera o princípio da proporcionalidade como evidente numa posição de primazia, na derivação de diferentes princípios jurídicos gerais do princípio do Estado de Direito, por sua "exigência da medida indicada, da adequação entre meio e fim, do meio mais idôneo ou da menor restrição possível do direito ou bem constitucionalmente protegido que, no caso concreto, tem de ceder perante outro bem jurídico igualmente protegido."

No posicionamento do aludido autor ${ }^{8}$, o princípio da proporcionalidade, na sua formulação mais geral, em que requer ou exige apenas uma relação com o risco que deveria ser afastado, aparece como um princípio aberto, porque nestes casos não é indispensável uma avaliação adicional. Não se trata aqui de outra coisa senão da idéia da justa medida do equilíbrio, que está indissociavelmente ligada à idéia de justiça.

Suas idéias e ensinamentos denotam a necessidade prevalecente, na atualidade, de adequação de princípios e cláusulas abertas no ordenamento jurídico às condições de vinculação e discricionariedade, para que, ao se traçarem caminhos paralelos desta dicotomia, conclua-se pelo ponto de intersecção que surge com os denominados conceitos jurídicos indeterminados.

Ainda sobre divergências de posicionamento com relação ao significado do princípio da proporcionalidade na teoria do direito, Humberto Bergmann ÁVILA ${ }^{9}$ alude aos ensinamentos de LARENZ que, ao atribuir um significado mais elástico aos princípios, considera-o um princípio material; atribuição da qual discorda, juntamente com KAUFMANN, ao considerar-lhe um princípio formal, que estabelece uma estrutura formal dos princípios envolvidos, ou seja, o meio escolhido deve ser adequado, necessário e não-excessivo.

\subsection{A intervenção estatal sob a égide do princípio da proporcionalidade}

Após o enfoque introdutório, onde discorreu-se a respeito do princípio da proporcionalidade na teoria do direito, cumpre-se atentar à sua definição. Luis G. Grandinetti Castanho de CARVALHO opta por lançar mão das palavras do Professor Nicolas Gonzales - Avellar SERRANO ${ }^{10}$, que o define do seguinte modo:

7 LARENZ, K. Metodologia de ciência do direito. 3.ed. Trad. José Lamego. Lisboa: Fundação Calouste Gulbenkian, 1997. p.603.

8 Ibidem, p.684.

9 ÁVILA, op. cit., p. 169-170.

10 SERRANO, N. Gonzales-Avellar apud Luis Gustavo Grandinetti Castanho de Carvalho. $O$ processo penal em face da constituição. 2.ed. rev. e ampl. Rio de Janeiro: Forense, 1998, p.73. "El principio de proporcionalidad es un principio general del Derecho que, en sentido muy amplio, obliga al operador juridico a tratar de alcanzar el justo equilibrio entre los interesses en conflicto... Exige, utilizando expresiones reiteradamente empleadas por el Tribunal Europeo de Derechos Humanos, que las restricciones de los derechos fundamentales se encuentren previstas por la ley, 
O princípio da proporcionalidade é um princípio geral de direito que, em sentido muito amplo, obriga o operador jurídico a tratar de alcançar o justo equilíbrio entre interesses em conflito ... Exige, utilizando expressões reiteradamente empregadas pelo Tribunal Europeu de Direitos Humanos, que as restrições dos direitos fundamentais se encontrem previstas pela lei, sejam adequadas aos fins legítimos a que se dirigem, e constituam medidas necessárias em uma sociedade democrática para alcançá-los. (tradição livre).

Tendência atual no direito dos países europeus é a convergência dos sistemas de common law e de direito administrativo. Esta convergência faz com que a intervenção estatal dê-se de modo à utilização de um princípio de controle exercido pelos tribunais quanto à adequação dos meios administrativos (sobretudo coativos) à prossecução do escopo e ao balanceamento concreto dos direitos ou interesses em conflito. O princípio da proporcionalidade é, dessarte, aplicado como standard jurisprudencial para recolocar a administração num plano menos distante em relação ao cidadão. Trata-se de controle de natureza equitativa que, não pondo em causa os poderes constitucionalmente competentes para a prática de atos de autoridade e a certeza do direito, contribui para a integração da justiça nos conflitos sociais.

O princípio da proporcionalidade, como conceito jurídico-administrativo, refere-se a benefícios decorrentes da decisão administrativa para o interesse público prosseguido pelo órgão decisor e os respectivos custos, medidos pelo inerente sacrifício de interesses dos particulares (o que também se pode chamar de racionalidade da decisão).

Esta racionalidade exsurge-se no campo de aplicação mais importante deste princípio, que é o da restrição dos direitos, liberdades e garantias por atos dos poderes públicos. No entanto, devido principalmente ao escopo do presente trabalho, cumpre-se salientar que no entanto, o domínio lógico de aplicação do princípio estende-se aos conflitos de bens jurídicos de qualquer espécie. Assim por exemplo, pode-se fazer apelo a ele no campo da relação entre a pena e a culpa no direito penal.

A restrição dos direitos, liberdades e garantias colimada através do princípio da proporcionalidade há de se adequar sempre ao pressuposto de legalidade, pois esta restrição não pode existir sem que esteja prevista em lei. Além do pressuposto de legalidade, é mister a adequação ao pressuposto de justificação teleológica, que limita a aplicação de qualquer restrição aos fins objetivados pela lei que a instituiu, ou seja, a restrição deve estar vinculada à proteção de outro interesse jurídico, fim primeiro de qualquer atividade legislativa.

\subsection{Requisitos de empregabilidade do princípio da proporcionalidade}

Os requisitos de empregabilidade do princípio da proporcionalidade devem ser analisados através do enfoque de subprincípios, que para serem melhor compreendidos, devem ser explicitados sob a ótica de alguns autores.

sean adecuadas a los fines legitimos a los que se dirijan, y constituyan medidas necesarias en una sociedad democratica para alcanzarlos". 
Luis Gustavo Grandinetti Castanho de CARVALHO ${ }^{11}$, ao discorrer sobre estes requisitos, assevera que:

Os requisitos são extrínsecos - judicialidade (requisito subjetivo) e a motivação (requisito formal) - e requisitos intrínsecos - constituídos por subprincípios da idoneidade, necessidade e da proporcionalidade em sentido estrito. A idoneidade constitui-se no exame de a medida constritiva ter ou não relação de causalidade ao fim pretendido, ou seja, ser idônea, apta, para atingir aquele fim. A necessidade, também compreendida como intervenção mínima, é a adequação do grau de eficácia das medidas. E, por último, a proporcionalidade em sentido estrito é o exame do confronto direto entre os interesses individuais e estatais, a fim de se estabelecer se é razoável exigir-se o sacrifício do interesse individual em nome do interesse coletivo.

Willis Santiago GUERRA FILHO ${ }^{12}$, por sua vez, aduz que:

O princípio da proporcionalidade, entendido como um mandamento de otimização do respeito máximo a todo direito fundamental, em situação de conflito com outro ou outros, na medida do jurídico e faticamente possível, tem um conteúdo que se reparte em três princípios parciais: princípios da proporcionalidade em sentido estrito ou máxima do sopesamento, princípio da adequação e princípio da exigibilidade ou máxima do meio mais suave.

$\mathrm{O}$ aludido autor refere-se ao primeiro como aquele que determina que se estabeleça uma correspondência entre o fim a ser alcançado por uma disposição normativa e o meio empregado, seja juridicamente a melhor possível. Os outros dois subprincípios; por sua vez, determinam que, dentro do faticamente possível, o meio escolhido se preste para atingir o fim estabelecido, mostrando-se assim, adequado. Além disso, esse meio deve se mostrar exigível, o que significa não haver outro, igualmente eficaz, e menos danoso a direitos fundamentais.

O modo de aplicação correto do princípio da proporcionalidade relaciona-se ao pressuposto de existência de valores estabelecidos positivamente em normas do ordenamento jurídico, principalmente aquelas com a natureza de um princípio fundamental, mas também requer um procedimento decisório, a fim de permitir a necessária ponderação em face dos fatos e hipóteses a serem considerados. Tal procedimento deve ser estruturado e institucionalizado de uma forma tal que garanta a maior racionalidade e objetividade possíveis da decisão, para atender ao imperativo de realização de justiça, que é imanente ao princípio.

João CAUPERS ${ }^{13}$ elucida que o conceito jurídico-administrativo de proporcionalidade decompõe-se em três níveis de apreciação:

a) A exigibilidade do comportamento administrativo, tendo este de constituir condição indispensável da prossecução do interesse público;

11 CARVALHO, L. G. G. C. de. O processo penal em face da constituição. 2.ed. rev. e ampl. Rio de Janeiro: Forense, 1998. pp.73-74.

12 GUERRA FILHO, op. cit., pp.67-68.

13 CAUPERS, op. cit., p.80. 
b) A adequação do comportamento administrativo à prossecução do interesse público visado;

c) A proporcionalidade em sentido estrito ou relação custos-benefícios, isto é, a existência de uma proporção entre as vantagens decorrentes da prossecução do interesse público e os sacrifícios inerentes dos interesses privados.

Após a explicitação dos requisitos de empregabilidade do princípio da proprocionalidade, pode-se sintetizá-los, em face do exposto, na seguinte maneira:

a) Subprincípio da conformidade ou adequação de meios: impõe que a medida adotada para a realização do interesse público deve ser apropriada à prossecução do fim ou fins a ele subjacentes. Conseqüentemente, a exigência de conformidade pressupõe a investigação e a prova de que o ato do poder público é apto para e conforme os fins justificativos de sua adoção. Trata-se de controlar a relação de adequação medida-fim;

b) Subprincípio da exigibilidade ou da necessidade: coloca a idéia de que o cidadão tem direito à menor desvantagem possível. Assim, exigir-se-ia sempre a prova de que, para a obtenção de determinados fins, não seria possível adotar outro meio menos oneroso para o cidadão. Este subprincípio não questiona, na maior parte dos casos, a adoção da medida (necessidade absoluta) mas sim a necessidade relativa, ou seja, se o legislador poderia ter adotado outro meio igualmente eficaz e menos desvantajoso para os cidadãos;

c) Subprincípio da proprocionalidade em sentido estrito: quando se chegar à conclusão da necessidade e adequação da medida coativa do poder público para alcançar determinado fim, mesmo neste caso deve perguntar-se se o resultado obtido com a intervenção é proporcional à carga coativa da mesma. Meios e fim são colocados em equação mediante um juízo de ponderação, com o objetivo de se avaliar se o meio utilizado é ou não desproporcionado em relação ao fim. Trata-se de uma questão de medida ou desmedida para se alcançar um fim: pesar as desvantagens dos meios em relação às vantagens do fim.

\subsection{Correlação principiológicas}

Em face do tema em questão, a análise do princípio da proporcionalidade em suas correlações com alguns outros princípios específicos do direito penal torna-se imprescindível.

$\mathrm{Na}$ atualidade, a tendência mundial em termos de direito penal diz respeito à tolerância e à descriminalização. Dois dos principais princípios que corroboram esta tendência são o da insignificância e o da intervenção mínima.

Francisco de Assis TOLEDO ${ }^{14}$ preleciona que "segundo o princípio da insignificância, que se revela por inteiro pela sua própria denominação, o direito penal, por sua natureza fragmentária, só vai até onde seja necessário para a proteção do bem jurídico.

Não deve ocupar-se de bagatelas". 
Seguindo suas explanações, constata-se a importância da proteção do bem jurídico, de acordo com níveis diferenciados de apreciação deste bem, considerado agora como um fim a que se destina a norma protetora.

Esta proteção se dá em níveis de ingerência mínima para a harmonização da vida social, e através de um juízo de proporcionalidade, adequa-se ao princípio da intervenção mínima. Marco Aurélio Costa Moreira de OLIVEIRA ${ }^{15}$ discorre a respeito deste princípio atestando que:

Toda intervenção, além dos limites da necessidade, desfigura o verdadeiro direito penal, compreendido apenas como uma indispensável atividade sancionatória do Estado. Em consequiência, há de se entender que o dever do Estado, ao estabelecer as normas penais, deve subordinar-se ao princípio da intervenção mínima, delimitado pelos critérios da necessidade e da realização da justiça substancial, punindo penalmente apenas aqueles que tenham atentado contra bens essenciais à vida social.

É de bom alvitre que se mencione, a título exemplificativo, que já na década de trinta, do século passado, a Dinamarca, como bem lembra Aníbal BRUNO ${ }^{16}$, possuía um Código Penal que admitia a analogia em matéria penal, que mesmo sendo usada de forma atenuada, era mantida dentro de limites consentâneos com a garantia dos direitos fundamentais. Atualmente, este país conta com baixos índices de criminalidade, configurando-se como um dos maiores exemplos de efetividade quanto à aplicação de princípios como o da intervenção mínima.

Ainda com relação aos bens jurídicos, é de suma relevância que sejam inseridos no contexto dos valores fundamentais. Valores fundamentais que correspondem a valores sociais básicos, que por sua importância, são elevados à categoria constitucional.

Somente a partir desta valoração essencial, estará o legislador apto a discernir entre o que seja realmente objeto de tutela penal estritamente necessária, para que possa usar com correção o critério da proporcionalidade, no intuito de proteger os cidadãos contra uma série de tipos penais desproporcionais ao fim a que se destinam.

O princípio da proprocionalidade, analisado sob a égide do direito penal, tem sua relevância limitada pela relevância da finalidade da pena para a sua estruturação e fixação. A finalidade da pena não estrutura a relação sem a correlação necessária com outros elementos, como tipicidade e culpabilidade.

A proprocionalidade só se aplica a um dos elementos do crime. Primeiro, a culpabilidade consubstancia um dos elementos do crime, e a pena pressupõe a culpa. Segundo, deve haver conguência entre a antijuridicidade e a culpa, na medida em que essa deve abranger todos os elementos objetivos do concreto ato antijurídico Terceiro, a pena deve ser correspondente à culpa, que lhe serve de limite. É somente nesse terceiro aspecto que a proporcionalidade pode ser substitutiva da culpabilidade. Portanto, ela torna-se relevante desde que sejam objetivamente estabelecidos os fins da pena e o elemento material com o qual ela deve estar em relação proporcional.

15 OLIVEIRA, M. A. C. M. de. O direito penal e a intervenção mínima. Revista Brasileira de Ciências Criminais. São Paulo: Revista dos Tribunais, ano 5, v.17, jan.-mar., 1997. p.152.

16 BRUNO, A. Direito penal. Rio de Janeiro: Forense, 1967. p.142. t.1. 
De acordo com o posicionamento de Humberto Bergmann ÁVILA" ${ }^{17}$, "essa considerações levam à qualificação da proporcionalidade como uma mera estrutura formal de aplicação do Direito a ser necessariamente posta em correlação com elementos substanciais normativos, sem os quais não passa de um esqueleto", opinião da qual extrai-se o mero aspecto formal do princípio da proporcionalidade, e que não encontra respaldo entre muitos dos autores citados, como GUERRA FILHO e Larenz.

\section{Limites à atividade discricionária dos contratos administrativos}

Primeiramente, é mister que se considere a necessidade de análise quanto aos atos discricionários emanados pela Administração Pública, cuja irrecorribilidade não pode, logicamente, ocorrer.

Em nenhum instante pode-se conceber uma parte qualquer da Administração Pública fora ou acima do ordenamento jurídico e é por esta razão mesma que se enumeram os princípios de direito, que existem justamente para colimar os abusos que possam advir de determinados atos arbitrários.

Os princípios configuram-se como limites, apesar de possuírem características não muito bem definidas, que podem ser objeto de inúmeras interpretações.

A violação de faculdades regradas é sempre mais clara e evidente. Daí exsurge a grande antinomia entre vinculação e discricionariedade, que por ter fortes cominações no modo de interpretação das sanções penais e administrativas constantes nos contratos administrativos, torna-se um ponto relevante, a ser perquirido por ocasião do presente trabalho.

Agustin GORDILLO ${ }^{18}$ asservera que "os principais limites que freiam a discricionariedade são os seguintes: a razoabilidade (a proibição de atuar arbitrária ou irracionalmente), o desvio de poder (proibição de atuar com uma finalidade imprópria) e a boa fé".

Todos estes limites norteiam-se por conceitos jurídicos indeterminados, característica que denota elementos paradoxais, pois como seria possível limitar a discricionariedade através de conceitos que, por sua natureza, são exatamente advindos de categorias imprecisas de definição?

A resposta a esta questão surge a partir do momento que se outorga a vinculação normativa àqueles conceitos, através da justificação analógica com referência a paradigmas pré-fixados através da jurisprudência, sempre utilizando-se de um critério de proporcionalidade nesta adequação.

O princípio da proporcionalidade, nesta seara, é uma importante conquista dos cidadãos no sentido da melhoria da eficácia na fiscalização do exercício dos poderes discricionários, na medida em que permite um controle objetivo destes, bem mais operativo do que o controle subjetivo, restrito à busca dos motivos determinantes da

17 ÁVILA, op. cit., p. 178.

18 GORDILLO, A. Princípios gerais de direito público. Trad. Marco Aurélio Greco. São Paulo: Revista dos Tribunais, 1977. p.183. 
decisão, no quadro da investigação do desvio de poder. Ressalva se faz, aqui, somente no sentido de que este controle objetivo irá se concretizar de modo cada vez mais efetivo, ao estar vinculado aos tipos que lhe são determinantes.

Manuel de Rivacoba y Rivacoba ${ }^{19}$ chama a atenção para a existência de regimes que chegam até mesmo à negação dos princípios imanentes ao direito penal, quando aduz:

Frente a regimes punitivos que sejam estranhos ou contrapostos a tais princípios, faz-se imperativo para a doutrina baseada em e conforme a eles, denunciá-los com insistência e severidade e postular com compelação sua substituição por leis que sejam respeitosas à dignidade humana e de sua própria e verdadeira entidade jurídica. À parte disto, nada de surpreendente tem que ordenamentos legais informados pelos autênticos princípios cardinais incorram em seu desconhecimento ou negação, isto é, que se desviem de suas exigências ou as contradigam, ao regular determinadas instituições, o que uma dogmática prestimosa descubrirá e colocará em relevo sem excessiva dificuldade, propondo de imediato a devida correção. (tradução livre).

A importância da dogmática para uma livre apreciação principiológica é, destarte, colocada em evidência, não somente pelo autor supracitado, mas por vários outros.

Quanto mais consistente forem as definições de categorias utilizadas na interpretação e na aplicação do direito, mais se ganhará em certeza e segurança jurídica. Finalidades essas, instituídas pelo ordenamento jurídico pátrio e que não podem ser ignoradas. É imperioso que um sistema jurídico é tanto mais coerente quanto mais específicas forem as conexões entre seus elementos, maior o número de conceitos gerais que possam explicá-lo e maior o número de casos que abranger.

Finalmente, cumpre-se assinalar algumas peculiaridades relacionadas ao contrato administrativo. Podem ocorrer hipóteses que demonstram que, em um vínculo constitutivo de direitos e obrigações recíprocos, onde deve prevalecer o equilíbrio econômico-financeiro entre as partes, uma entidade pública pode ter o interesse de extrair o máximo de vantagens, eximindo-se de todos os encargos de que conseguisse se evadir. Procedimentos deste cunho denotam o total descaso quanto ao interesse público, finalidade máxima deste tipo de contrato.

Alexandre Santos de Aragão ${ }^{20}$, em recente artigo, faz considerações importantes sobre o princípio da proporcionalidade e a supremacia do interesse público:

19 RIVACOBA, M. de R. y. Introducción al estudio de los principios cardinales del derecho penal. Revista brasileira de ciências criminais. São Paulo: Revista dos Tribunais, ano 8, v.32, out.-dez. 2000 , p.54. "Frente a regímines punitivos que sean extraños o contrapuestos a tales principios se hace imperativo para la doctrina basada en y conforme con ellos denunciarlos con insistencia y severidad y postular con apremio su substitución por leyes que sean respetuosas de la dignidad humana y de su propria y verdadera entidad jurídica. Aparte de esto, nada de sorprendente tiene que cuerpos legales informados por los auténticos principios cardinales incurvan en su desconocimiento o negación, es decir, que se desvien de sus exigencias o las contradigan, al regular determinadas instituciones, lo que una dogmática acuciosa descubrirá y ponderá de relieve sin excesivas dificultades, proponiendo de inmediato la debida corrección".

20 ARAGÃO, A. S. de. O princípio da proporcionalidade no direito econômico. Revista de Direito Administrativo. Rio de Janeiro: Renovar, v.223, jan.-mar., 2011. pp.214-215. 
A doutrina contemporânea refere-se à impossibilidade de rigidez na prefixação do interesse público, sobretudo pela relatividade de todo padrão de comparação. Deve-se salientar, contudo, que não se está a negar a importância jurídica do interesse público. O que deve ficar claro, é que mesmo nos casos em que ele legitima uma atuação estatal restritiva específica, deve haver uma ponderação relativamente aos interesses privados e à medida de sua restrição. É essa ponderação para atribuir máxima realização aos interesses envolvidos o critério decisivo para a atuação administrativa.

Dessarte, o princípio da proporcionalidade traz a justa medida para o critério de ponderação aludido acima, viabilizando, assim, o equilíbrio econômico-financeiro do contrato administrativo.

\section{Conclusões}

Cumpre-se, primeiramente, neste escorço conclusivo, atentar ao problema da garantia constitucional no direito punitivo.

A partir de contestações feitas no final da década de setenta pelo ilustre Francesco C. PALAZZO ${ }^{21}$, o qual afirmava que já naquele momento:

A tendência a uma progressiva sobreposição entre o direito punitivo administrativo e o direito criminal traz importantes manifestações também em nível legislativo, se não no sentido de uma oportunidade expressa de posicionamento do legislador favorável à aplicação da disciplina e dos princípios penalísticos ao direito administrativo, naquele sentido, não menos significativo, de uma progressiva redução da sanção administrativa, à exceção que no campo fiscal, há vantagem de um maior recurso à sanção penal. Hoje se assiste, no entanto, a uma inversão nesta tendência, sendo particularmente viva e forte a aspiração à descriminalização. (tradução livre).

$\mathrm{O}$ aspecto sancionatório disciplinado na lei $8.666 / 93$, sobre os contratos administrativos, vai contra a tendência crescente de descriminalização que vem ocorrendo em outros sistemas jurídicos do mundo.

Desta tendência, extrai-se que a Administração Pública, quando impõe pena ao particular deve, necessariamente, atuar da maneira menos lesiva, pautando-se pelas balizas da necessidade e da adequação. A utilização imoderada da competência punitiva, tendência esta que vem se manifestando de modo até mesmo acirrado diante de inúmeros exemplos de tipificações penais com os quais se deparam os cidadãos

21 PALAZZO, F. C. II principio di determinateza nol diritto penale. Padova: Cedam, 1979. p.199-2000. "La tendenza ad una progressiva sovrapposizione tra il diritto punitivo amministrativo e il diritto criminale eble importanti manifestazioni anche a livello legislativo, se non nel senso di una espressa presa di posizione del legislatore a favore dell'applicazione della disciplina e dei principi penalistia al diritto amministrativo, certamente in quello, non meno significativo, di una progressiva riduzione delle sanzioni amministrative, ad eccezione che nel campo fiscale, a vantaggio di un sempre piú impomente ricorso alla sanzione penale. Oggi si assiste, però, ad una inversione di quella tendenza, essendo particorlamente viva e forte l'aspirazione alla decriminalizzazione." 
brasileiros na atualidade, propende à ilegitimidade, com grande probabilidade ao arbítrio.

A Administração Pública, ao impor sanções durante o desenrolar dos contratos administrativos. e ao pronunciar pena que não se coadune com a gravidade da falta imputada. dele estar sujeita ao controle do juiz.

O Poder Judiciário tem reputado a proporcionalidade na perquirição de sanções administrativas, mas esta reputação deve ser mantida quando ocorram imposições de sanções penais nos contratos administrativos.

É incontestável que a Administração deve observar sempre, nos casos concretos, as exigências de proporcionalidade, principalmente nos casos em que dispõe de espaços de discricionariedade.

Como nas hipóteses de uma estreita vinculação imposta por lei, o princípio da proporcionalidade deve ser analisado mais a partir da própria lei do que do ato concreto da Administração, os aspectos submetidos à discrição do administrador sofrem redução.

Estes aspectos devem ser analisados e interpretados, tanto pelo legislador, como pelo administrador e o juiz a partir da apreensão de paradigmas representados pelos princípios correlacionados ao princípio da proporcionalidade em todas as suas inserções (quer sejam no direito constitucional, administrativo e penal).

Não se torna fundamental, sob este prisma, considerar o princípio da proporcionalidade somente sob a ótica formal, mas principalmente sob o prisma de sua inserção substancial no modo de trazer à tona valores que demonstrem a premente necessidade de adequação de tipos penais à realidade para a qual foram criados.

$O$ fato de existirem conceitos jurídicos indeterminados nesta seara, é somente mais um motivo para se olvidar à busca incessante de maneiras até mesmo analógicas de se definirem as especificidades não pela sua forma, mas pela sua finalidade.

A constatação da existência de valores supremos constitucionais que influenciam todos os demais ramos do direito, traz à teoria dos contratos administrativos mais uma certeza na afirmação de sua busca na persecução do interesse público.

Esta persecução não se efetivará através de percalços advindos de aspectos punitivos que a lei possui. Ela se efetivará somente através de um juízo de proporcionalidade, que tornará a adequação meio-fim um modo de proteção inestimável aos direitos fundamentais dos cidadãos.

Quando isto ocorrer, o princípio da proporcionalidade poderá ser elevado à categoria de valor supremo da Constituição, possuindo, então, força vinculante para colimar todas as situações de desequilibrio, inclusive aquelas inerentes às sanções constantes nos contratos administrativos.

\section{Referências bibliográficas}

ARAGÃO. Alexandre Santos de. O princípio da proporcionaliade no direito econômico. Revista de Direito Administrativo. Rio de Janeiro: Renovar, v.223, jan. - mar.. 2001, pp.199-230. 
ÁVILA, Humberto Bergmann. A distinção entre princípios e regras e a redefinição do dever de proporcionalidade. Revista de Direito Administrativo. Rio de Janeiro: Renovar, v.215, jan. - mar., 1999, p.151-179.

BETTIOL, Giuseppe. Instituições de direito e processo penal. Trad. Manuel da Costa Andrade. Coimbra: Coimbra Editora, 1974.

BRUNO, Anibal. Direito penal. Rio de Janeiro: Forense, 1967, t.1.

CANOTILHO, J. J. Gomes. Direito constitucional e teoria da constituição. 2.ed. Coimbra: Almedina, 1998.

CARVALHO, Luis Gustavo Grandinetti Castanho de. O processo penal em face da constituição. 2.ed. rev. e ampl. Rio de Janeiro: Forense, 1998.

CAUPERS, João. Introdução ao direito administrativo. Lisboa: Ancora, 2000.

FRAGOSO, Heleno Cláudio. Lições de direito penal. 11.ed. rev. Rio de Janeiro: Forense, 1987.

FREIRE, Reis. Lições objetivas de direito administrativo. São Paulo: Saraiva, 1999.

GORDILlO, Agustin. Princípios gerais de direito público. Trad. Marco Aurélio Greco. São Paulo: Revista dos Tribunais, 1977.

GUERRA FILHO, Willis Santiago. Processo constitucional e direitos fundamentais. São Paulo: Editora Celso Bastos, 1999.

LARENS, Karl. Metodologia da ciência do direito. 3.ed. Trad. José Lamargo. Lisboa: Fundação Calouste Gulbenkian, 1997.

LUISI, Luiz. Direito humanos - repercussões penais. Revista Brasileira de Ciências Criminais. São Paulo: Revista dos Tribunais, ano 6, v.21, jan. - mar., 1998. Os princípios constitucionais penais. Porto Alegre: Sérgio Antônio Fabris Editor, 1991.

MEDAUAR, Odete. Direito administrativo moderno. 4.ed. rev. atual. e ampl. São Paulo: Revista dos Tribunais, 2000.

MELlO, Celso Antônio Bandeira de. Contrato administrativo: fundamento da preservácão do equilíbrio econômico financeiro. Revista de Direito Administrativo. Rio de Janeiro: Renovar, v.211, jan.-mar., 1998. pp.21-29.

Curso de direito administrativo. 12.ed. rev. atual. e ampl. São Paulo: Malheiros, 2000.

NOBRE JÚNIOR, Edilson Pereira. Sanções administrativas e princípios de direito penal. Revista de Direito Administrativo. Rio de Janeiro: Renovar, v.219, jan.mar., 2000. pp.127-151.

OLIVEIRA, Marco Aurélio Costa Moreira de. $O$ direito penal e a intervenção mínima. Revista Brasileira de Ciências Criminais. São Paulo: Revista dos Tribunais, ano 5, v.17, jan.-mar., 1997. pp.145-152.

PALAZZO, Francesco C. Il principio di determinatezza nel diritto penale. Padova: Cedam, 1979.

Valores constitucionais e direito penal. Trad. Gérson Pereira dos Santos Porto Alegre: Sérgio Antônio Fabris Editor, 1989.

RIVACOBA, Manuel de Rivacoba y. Introducción al estudio de los principios cardinales del derecho penal. Revista Brasileira de Ciências Criminais. São Paulo Revista dos Tribunais, ano 8, v.32, out.-dez., 2000, pp.39-54. 
ROMANO, Santi. Principios de direito constitucional geral. Trad. Maria Helena Diniz. São Paulo: Revista dos Tribunais, 1977.

ROPPO, Enzo. O contrato. Trad. Ana Coimbra e M. Januário C. Gomes. Coimbra: Almedina, 1988.

TOLEDO, Francisco de Assis. Princípios básicos de direito penal. 5.ed. São Paulo: Saraiva, 1994. 